Journal of Applied Pharmaceutical Science Vol. 5 (12), pp. 117-121, December, 2015

Available online at http://www.japsonline.com

DOI: $10.7324 / \mathrm{JAPS} .2015 .501220$

ISSN 2231-3354 (cc) BY-NC-sA

\title{
A simple spectrophotometric quantitative determination of Cilostazol in bulk and pharmaceutical dosage forms using DNPH reagent
}

\author{
Siddappa Anjanappa Kuruba*, Prashant Chandrakant Hanamshetty \\ Department of Chemistry, Gulbarga University, Gulbarga -585106, Karnataka India.
}

\begin{tabular}{|c|c|}
\hline ARTICLE INFO & ABSTRACT \\
\hline Article history: & \multirow{10}{*}{$\begin{array}{l}\text { A simple, sensitive, cost effective spectrophotometric method developed and validated for the determination of } \\
\text { Cilostazol (CIL), in bulk drug and its pharmaceutical formulations. The method is rely on the formation of a } \\
\text { hydrazone with } 2,4-\text { dinitrophenylhydrazine }(\mathrm{DNPH}) \text {; the reaction of drug with reagent gives a bright yellow } \\
\text { colour. The obtained coloured species absorbance was measured at its absorption maximum }\left(\lambda_{\max }\right) 355 \mathrm{~nm} \text {. The } \\
\text { Beer's law has been obeyed in the concentration range } 2-20 \mu \mathrm{g} / \mathrm{ml} \text {. The optical parameters were calculated as } \\
2.2980 \times 10^{4}\left(\mathrm{~L} \mathrm{~mol}{ }^{-1} \mathrm{~cm}^{-1}\right), 0.0161\left(\mu \mathrm{g} / \mathrm{cm}^{2}\right) \text {, molar absorptivity and Sandell sensitivity respectively. The } \\
\text { analytical parameters of interest LOD and LOQ of the proposed method were calculated } 0.1079(\mu \mathrm{g} / \mathrm{ml}), 0.3594 \\
(\mu \mathrm{g} / \mathrm{ml}) \text { respectively. All the variables were examined to optimize the reaction conditions. There was no } \\
\text { interference observed in the presence of common pharmaceutical excipients. The validity of the method was } \\
\text { established by analyzing CIL in its pharmaceutical formulations and critically tested for its accuracy by statistical } \\
\text { tests. Good recoveries were obtained by the developed method; the obtained results were critically analyzed and } \\
\text { successfully employed for the determination of CIL in its pharmaceutical dosage forms. }\end{array}$} \\
\hline 1/08/2015 & \\
\hline Revis & \\
\hline n: 19/09/2015 & \\
\hline Available online: $27 / 12 / 2015$ & \\
\hline Key words: & \\
\hline Cilostazol, DNPH, & \\
\hline & \\
\hline antiplatelet- agregation, & \\
\hline Validation. & \\
\hline
\end{tabular}

\section{INTRODUCTION}

Chemically Cilostazol (CIL) is 6-[4-(1-cyclohexyl-1Htetrazolyl-5-yl) butoxy]-3, 4-dihydro-2(1H)-quinoline (Fig.1). CIL is a quinolinone derivative that inhibits cellular phosphodiesterase (more specific for phosphodiesterase III). It is an anti-platelet agent and is designated chemically as hepatic cytochrome P-450 enzymes, mainly 3A4, extensively metabolizes CIL and metabolites largely excreted in urine (Jadhav et al., 2007). It affects both vascular beds and cardiovascular function, could have pharmacodynamic interactions with other inhibitors of platelet function and pharmacokinetic interactions because of effects of other drugs on its metabolites by CYP3A4 or CYP2C19 (Physician desk reference, 2005). A literature survey revealed few highperformance liquid chromatographic (HPLC) methods for quantitative determination of CIL and its metabolites in human plasma (Fu et al., 1999), human urine (Tata et al., 2001) and human liver (Tata et al., 1998). Recently, a validated LC method was developed and reported (Dwi et al., 2004; Yeon et al., 2005;

\footnotetext{
* Corresponding Author

Email: siddappa_65@rediffmail.com
}

Nirogi et al., 2006; Basniwal et al., 2008) for the determination of CIL in tablets. Spectrflourimetric (Attia et al., 2011) and Spectrophotometric (Basniwal et al., 2010) analytical method for CIL is available in literature and it was felt necessary to develop a spectrophotometric method for determination and quantitative estimation of CIL. This paper describes the assay and validation method for accurate quantification of CIL in pure and tablet formulations.

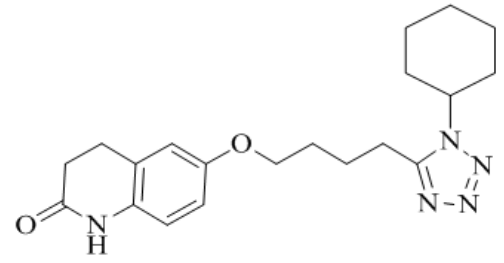

Fig 1: Chemical Structure of Cilostazol.

Although there are several highly sophisticated instrumental methods were reported but are suffered by time of analysis, cost per analysis, sophistication and most importantly the skilled analyst to handle the instruments. The present method offers a simple, sensitive, cost effective method for the determination of CIL in any common QC laboratory. 


\section{MATERIALS AND METHOD}

Apparatus

All spectrophotometric measurements were carried out using a double beam T90+ UV-Spectrophotometer (PG Instruments Ltd. USA) with quartz cells of $1 \mathrm{~cm}$ thickness. Officially, calibrated Pyrex glassware was used throughout this study.

\section{Materials and reagents}

All the chemicals used were of analytical grade. All the solutions were prepared freshly and deionised water is used throughout the experiment. Cilostazol bulk drug obtained from Lupin Laboratories Ltd. certified to contain $99.7 \%$ of active ingredient, which has been used as a reference substance, as received without further purifications. 2,4-dinitrophenylhydrazine (DNPH) was procured from Sd-Fine chemicals $99.5 \%$ purity and $\mathrm{HCl}$ procured from Sd-Fine chemicals $35 \%$ purity. Methanol AR grade procured from Sd-Fine chemicals.

Cilostazol tablets were purchased from pharmaceutical store with different contents and different makes such as Cilodac ${ }^{\circledR}$ (50 mg CIL) and Cilodac ${ }^{\circledR}$ (100 mg CIL) from Lupin Laboratory Ltd.

\section{Preparation of $0.5 \%(\mathrm{w} / \mathrm{v})$ DNPH solution}

Accurately weighed $250 \mathrm{mg}$ of DNPH in a $50 \mathrm{ml}$ volumetric flask, added $20 \mathrm{ml}$ of methanol swirled to mix then the solution made up to the mark with methanol.

\section{Preparation of standard stock solution:}

Accurately weighed $(0.001 \mathrm{~g}) 10 \mathrm{mg}$ of the reference standard in $10 \mathrm{ml}$ volumetric flask, added $5 \mathrm{ml}$ methanol swirled to mix and brought to the mark with methanol. The apparent concentration reached to $1000 \mu \mathrm{g} / \mathrm{ml}$. further dilutions made to obtain the working standard stock solution $100 \mu \mathrm{g} / \mathrm{ml}$.

\section{Preparation of sample solution}

i. $\quad$ Cilodac $^{\circledR}$ tablets (10 tablets) labeled claim to contain 50 $\mathrm{mg}$ of CIL, average weight of each tablet was $255 \mathrm{mg}$ were triturated and made a fine powder, mixed it well for homogeneity. A portion $(510 \mathrm{mg})$ of the fine powder was transferred to contain $100 \mathrm{mg}$ of the CIL in to a beaker and dissolved with $20 \mathrm{ml}$ of deionised water and mixed well. This solution was filtered through a Whatmann filter paper No.41, in to a $100 \mathrm{ml}$ volumetric flask. The filtrate was made up to the mark with methanol.

ii. $\quad$ Cilodac ${ }^{\circledR}$ tablets (10 tablets) labeled claim to contain 100 $\mathrm{mg}$ of CIL, average weight of each tablet was $370 \mathrm{mg}$ were triturated and made a fine powder, mixed it well for homogeneity. A portion $(370 \mathrm{mg}$ ) of the fine powder was transferred to contain $100 \mathrm{mg}$ of the CIL in to a beaker and dissolved with $20 \mathrm{ml}$ of deionised water and mixed well. This solution was filtered through a Whatmann filter paper No.41, in to a $100 \mathrm{ml}$ volumetric flask. The filtrate was made up to the mark with methanol.

\section{General procedure for the determination of Cilostazol}

Variable aliquots of working standard solution containing $2-20 \mu \mathrm{g} / \mathrm{ml}$ of CIL were transferred in to series $10 \mathrm{ml}$ volumetric flasks. To each flask $1 \mathrm{ml}$ of concentrated $\mathrm{HCl}$ was added, mixed the solution mechanically and then added $1 \mathrm{ml}$ of $0.5 \%$ DNPH solution then the flasks are heated on a water bath for $10 \mathrm{~min}$. there is a formation of yellow coloured hydrazone, then the flasks are allowed to cool to room temperature and the solutions made up to the mark with water. The coloured species absorbance was measured at $355 \mathrm{~nm}$ using reagent as a blank. The formation of hydrazone is shown in Scheme 1(Dawood 2012). The calibration graph was prepared by plotting absorbance versus concentration of drug and the concentration of unknown was read from the calibration graph or computed from the regression equation derived from the Beer's law data (Siddappa et al., 2013).

The same procedure was followed for the determination of CIL in the tablet formulations and the content of the tablets were calculated by using regression equation (Siddappa and Hanamshetty, 2014).
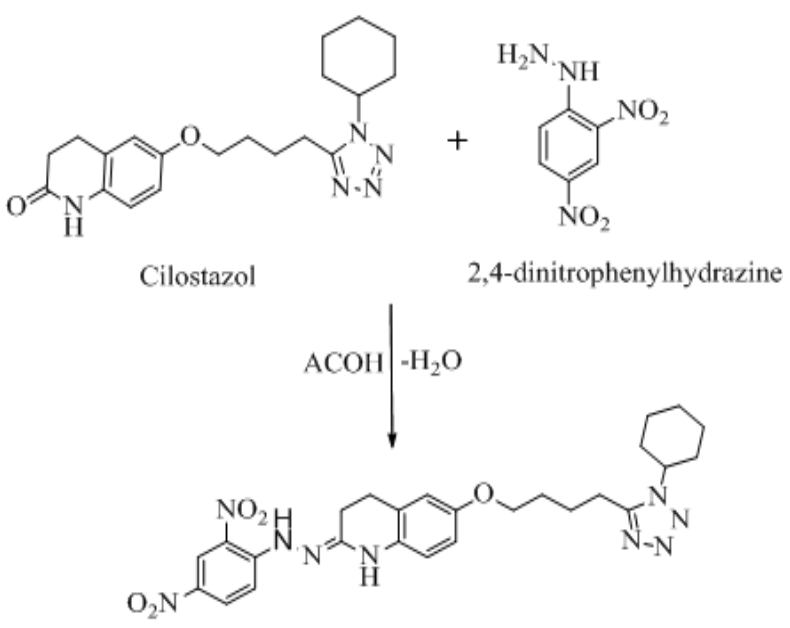

hydrazone

Scheme. 1: Possible reaction sequence.

\section{RESULT AND DISCUSSION}

\section{Determination of absorption maxima $\left(\lambda_{\max }\right)$}

To determine the $\lambda_{\max }$ of the colored species, $1 \mathrm{ml}$ of 100 $\mu \mathrm{g} / \mathrm{ml}$ of the CIL was added to a $10 \mathrm{ml}$ volumetric flask and $1 \mathrm{ml}$ of concentrated $\mathrm{HCl}$, mixed the contents mechanically then added $1 \mathrm{ml}$ of $0.5 \%$ DNPH solution then the flasks are heated on a water bath for $10 \mathrm{~min}$. there is a formation of yellow coloured hydrazone, then the flasks are allowed to cool to room temperature and the solutions made up to the mark with methanol. The coloured species was measured against reagent blank in the range of $300 \mathrm{~nm}$ to $600 \mathrm{~nm}$. The $\lambda_{\max }$ of the complex was found to be 355 $\mathrm{nm}$. Absorption spectrum of the proposed method was shown in Fig.2. Under the experimental conditions each reagent blank showed a negligible absorbance at the corresponding $\lambda_{\max }$. 


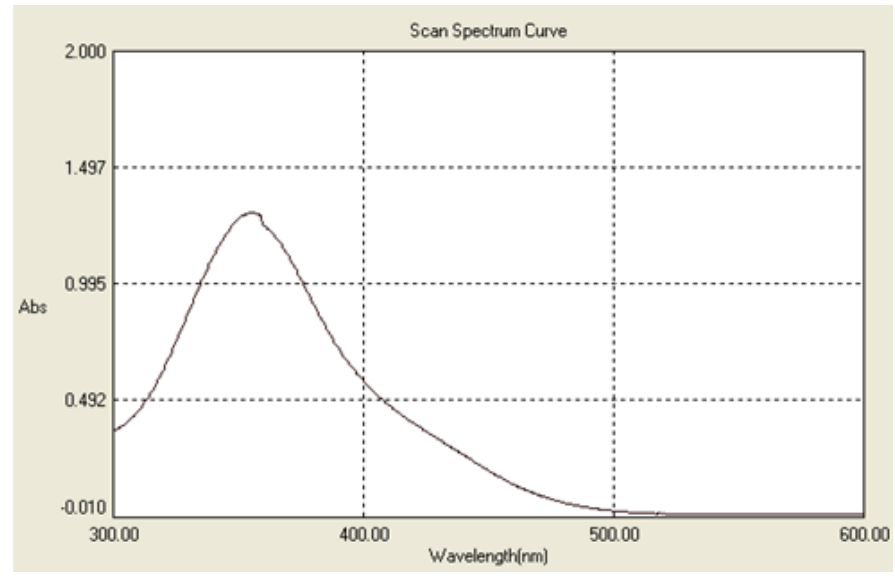

Fig 2: Absorption spectrum of the coloured species.

\section{Investigation of assay parameters}

Optimum reagent concentrations required for the formation of sensitive and quantitative coloured products were determined by varying one reagent concentration and fixing the concentrations of other reagents and its effect on absorbance was measured at $355 \mathrm{~nm}$.

\section{Effect of heating time}

To study the effect of heating time for the development of maximum colour, the contents of the mixture were heated for up to $30 \mathrm{~min}$. at $80 \pm 1^{\circ} \mathrm{C}$. The intensity of the colour developed was measured at room temperature after the dilution to $10 \mathrm{ml}$ with deionised water. It is apparent from the investigation that the maximum intensity of colour was obtained after $10 \mathrm{~min}$ of heating and remained constant. Therefore the optimum heating time was fixed to $10 \mathrm{~min}$.

\section{Effect of reagent concentration}

The effect of concentration of DNPH solution and $\mathrm{HCl}$ were studied on the related absorbance values. Different concentrations of DNPH solutions from $0.1 \%$ to $0.6 \%$ were studied. Volumes of $0.2-2.0 \mathrm{ml}$ of DNPH $(0.5 \%)$ and $0.5-3.0 \mathrm{ml}$ of concentrated $\mathrm{HCl}$ were examined. The investigations showed that $1.0 \mathrm{ml}$ of $\mathrm{DNPH}$ and $2.0 \mathrm{ml}$ of concentrated $\mathrm{HCl}$ gave maximum absorbance. There is no change in intensity of the colour any further with the increasing amounts of DNPH and concentrated $\mathrm{HCl}$. So the $1.0 \mathrm{ml}$ of $\mathrm{DNPH}$ and $1.0 \mathrm{ml}$ of concentrated $\mathrm{HCl}$ were chosen throughout the experiment.

\section{Interference studies}

To study the potential interference from the commonly used excipients and other additives such as glucose, lactose, starch, sodium starch glycolate, cellulose, magnesium stearate and ascorbic acid recovery studies were carried out. Under the experimental conditions employed, to a known amount of drug. The recovery studies suggest that there was no significant interference from the excipients on the assay of the drug.

\section{VALIDATION OF THE METHOD}

\section{Detection and Quantification limits}

According to the Analytical Methods Committee the detection limit (LOD) is the concentration of drug corresponding to a signal equal to the blank mean $\left(\mathrm{Y}_{\mathrm{B}}\right)$ plus three times the standard deviation of the blank $\left(\mathrm{S}_{\mathrm{B}}\right)$. Quantification limit (LOQ) is the concentration of drug corresponds to the blank mean plus ten times the standard deviation of the blank (Siddappa and Hanamshetty., 2015)

. The LOD and LOQ values for CIL were found to be 0.1079 $\mu \mathrm{g} / \mathrm{ml}, 0.3594 \mu \mathrm{g} / \mathrm{ml}$ respectively.

\section{Quantification}

The optical characteristics such as Beer's law limits, Sandell sensitivity and molar absorptivity were calculated for the proposed method and the results are summarized in Table 1. Regression analysis of the Beer's law plot at their $\lambda_{\max }$ revealed a good correlation as shown in Fig 3.

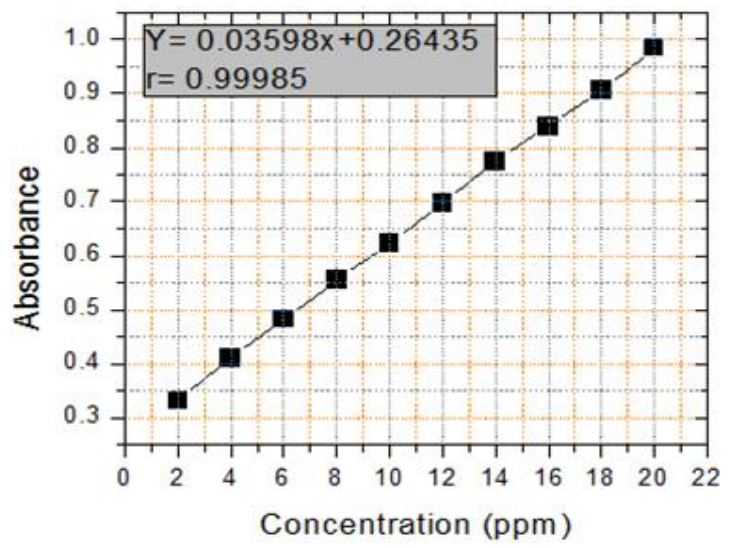

Fig. 3: Beer's law calibration curve.

Table 1: Optical and Regression characteristics, precision and accuracy of the proposed method.

\begin{tabular}{clc}
\hline Sl.No. & Parameters & Value \\
\hline 1 & $\lambda_{\max }(\mathrm{nm})$ & 355 \\
2 & Beer's law limit $(\mu \mathrm{g} / \mathrm{ml})$ & $2-20$ \\
3 & Sandell sensitivity $\left(\mu \mathrm{g} / \mathrm{cm}^{2} / 0.001 \mathrm{abs}\right.$. unit $)$ & 0.0161 \\
4 & Molar absorptivity $\left(\mathrm{L} \mathrm{mole}{ }^{-1} . \mathrm{cm}^{-1}\right)$ & $2.2980 \times 10^{4}$ \\
5 & Stability of Color $($ hours $)$ & 8 \\
6 & Regression equation & $\mathrm{y}=0.03598 \mathrm{x}+$ \\
& & 0.26435 \\
7 & Correlation coefficient & 0.99985 \\
9 & \% Relative standard deviation & 0.21401 \\
9 & \% Range of errors & $0.6220 \pm 1.202 \times 10^{-3}$ \\
& 0.05 \% & $0.6220 \pm 0.223 \times 10^{-3}$ \\
10 & $0.01 \%$ & 0.1079 \\
11 & Limit of detection $(\mu \mathrm{g} / \mathrm{ml})$ & 0.3594 \\
\hline
\end{tabular}

For the regression analysis we have selected different concentration sets but the best fit curve was obtained in the concentration range 2 to $20 \mu \mathrm{g} / \mathrm{ml}$ of standard CIL. For the verification of Beer's law we have taken a series of $10 \mathrm{ml}$ volumetric flasks and added the working standard solution (100 
$\mu \mathrm{g} / \mathrm{ml}$ ) serially from $0.2 \mathrm{ml}$ to $2.0 \mathrm{ml}$ followed by added all the reagents as mentioned in the assay procedure.

Graph of absorbance versus concentration plotted and are described by the regression equation $\mathrm{Y}=\mathrm{bx}+\mathrm{a}$ (where ' $\mathrm{Y}$ ' is the absorbance, ' $\mathrm{b}$ ' is the slope, ' $\mathrm{x}$ ' is the concentration of the drug in $\mu \mathrm{g} / \mathrm{ml}$ and ' $\mathrm{a}$ ' is the intercept) obtained by least squares method. The results were summarized in Table 1.

\section{Accuracy precision and recovery studies}

The accuracy and precision of the proposed method was evaluated by performing five replicate determination of CIL in pure form at three different concentrations $(12,14$ and $16 \mu \mathrm{g} / \mathrm{ml})$ by short term (intra-day) precisions as shown in Table 2. The standard analytical errors, relative standard deviations (\%RSD) and recoveries obtained in the intra-day analysis for the proposed method were found to be acceptable. Thus the proposed method is effective for the determination of CIL.

Table 2: Evaluation of the accuracy and precision of the proposed method by intra-day assay.

\begin{tabular}{ccccc}
\hline \multicolumn{5}{c}{ Observed concentration of CIL $(\boldsymbol{\mu g} / \mathbf{m l})$} \\
\hline \multirow{2}{*}{$\begin{array}{c}\text { Concentration of } \\
\text { CIL }(\boldsymbol{\mu g} / \mathbf{m l})\end{array}$} & Mean $^{*}$ & Error $(\%)$ & RSD $(\%)$ & Recovery $(\%)$ \\
\hline 12 & 11.990 & 0.034 & 0.110 & 99.92 \\
14 & 14.170 & 0.039 & 0.114 & 101.2 \\
16 & 15.950 & 0.035 & 0.093 & 99.68 \\
\hline
\end{tabular}

*For five determinations

The accuracy of the proposed method was further checked by performing recovery experiments through standard addition technique. For this purpose, a known amount of pure CIL was added to pre-analyzed dosage forms and then determined by the recommended procedure. The results are as shown in Table 3 . The values of mean recovery and relative standard deviation (\%RSD) were in the range of $99.99-100.0 \%$ and $0.032-0.033 \%$ respectively. This indicates the reproducibility of the method. No interference was observed from the common excipients of tablet.

Table 3: Determination of CIL in pharmaceutical formulation by standard addition technique.

\begin{tabular}{cccccc}
\hline $\begin{array}{c}\text { Amount } \\
\text { of drug } \\
\text { before } \\
\text { addition } \\
(\boldsymbol{\mu g})\end{array}$ & $\begin{array}{c}\text { Amount } \\
\text { of drug } \\
\text { added } \\
(\boldsymbol{\mu g})\end{array}$ & $\begin{array}{c}\text { Theoretical } \\
\text { amount }(\boldsymbol{\mu g})\end{array}$ & $\begin{array}{c}\text { Mean } \\
\text { amount } \\
\text { recovered } \\
(\boldsymbol{\mu g})\end{array}$ & $\begin{array}{c}\text { Mean \% } \\
\text { of } \\
\text { recovery } \\
(\mathbf{n = 5})\end{array}$ & RSD\% \\
\hline 5 & 10 & 15 & 14.99 & 99.99 & 0.032 \\
5 & 20 & 25 & 25.00 & 100.0 & 0.033 \\
\hline
\end{tabular}

\section{Applicability of the Method}

The proposed method applied to the analysis of CIL in pharmaceutical dosage forms and the results were statistically compared with reference method by calculating the student's $t$ values. The evaluated t- values were less than the tabulated values at the 95\% confidence level for five degrees of freedom, as revealed by the results complied in Table 4 . This actually suggests that the proposed method is accurate and precise as the reference method.
Table 4: Results of analysis of tablet formulation containing CIL. $\%$ Found \pm SD

\begin{tabular}{|c|c|c|c|c|c|}
\hline 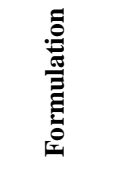 & 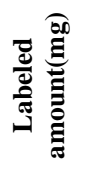 & 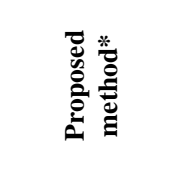 & 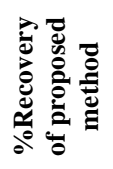 & 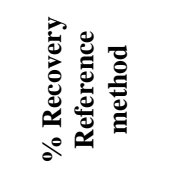 & 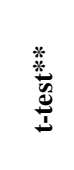 \\
\hline Cilodac $^{\circledR}$ & 50 & $49.75 \pm 0.0019$ & 99.50 & $100.2 \pm 1.43^{\mathrm{a}}$ & 0.437 \\
\hline Cilodac $^{\circledR}$ & 100 & $101.2 \pm 0.0013$ & 101.2 & $100.08 \pm 0.16^{\mathrm{b}}$ & 0.283 \\
\hline
\end{tabular}

* Recovery amount was the average of five determinations. **The t-value from table is 2.776 at 95\% level. a) (Basniwal et al., 2008) and b) (Attia et al., 2011) are the contents of CIL in reference methods

\section{CONCLUSIONS}

The proposed method was quite simple and do not require any pre-treatment of the drug and tedious extraction procedure. The method has a wider range with good accuracy and precision. Hence, the data presented in the manuscript demonstrate that the proposed method was accurate, precise, linear, selective and offers advantages of reagent availability and stability, less time consumption and highly sensitive. Thus it can be extended for routine analysis of CIL in pharmaceutical industries and hospitals and research laboratories. Unlike the LC/MS procedure and HPLC procedures, the UV-visible spectrophotometer instrument is simple and not of highly expensive on the other hand in simplicity and user friendly the method could be considered superior in comparison with the previously reported methods. Moreover the method is free from interferences by common additives and excipients.

\section{ACKNOWLEDGEMENT}

The authors are grateful to Lupin Laboratories Ltd. Mumbai for providing gift sample of reference grade CIL and also the Chairman of the Department of Chemistry, Gulbarga University, Gulbarga, for providing all facilities, support and encouragement to carry out the study. Authors are thankful to USIC Department Gulbarga University, Gulbarga, for necessary instrumentation help. One of the authors extends his sincere acknowledgment to the UGC for providing financial assistance in the form of BSR Fellowship (No.F.7-226/2009 (BSR) Dated: 0608-2014).

\section{REFERENCES}

Attia M S, Mahmoud W H, Youssef A O, Mostafa M S. Cilostazol determination by the enhancement of the green emission of Tb3+ optical sensor. J Fluoresc, 2011; 21: 2229-2235.

Basniwal P K, Kumar V, Kumar P, Shrivastava, Jain D. Spectrophotometric determination of cilostazol in tablet dosage form. Trop J Pharm Res, 2010; 9(5): 499-503.

Basniwal P K, Shrivastava P K, Jain D. Hydrolytic degradation profile and RP-HPLC estimation of cilostazol in tablet dosage form. Indian J Pharm Sci, 2008, 70(2): 222-224.

Dawood R S. Synthesis, characterization and biological activity study of some new schiff bases derived from phenyl quinoline-2(1H)-one. Al-Anbar J Vet Sci, 2012; 5 (2): 114-122.

Dwi A, Lestari, Tini, Palupi, Bertha, Oktarina, Mochammad, Yuwono, Indrayanto G. HPLC determination of cilostazol in tablets, and its validation. J Liq Chrom Relat Tech, 2004; 27: 2603-2612. 
Fu C J, Tata P N, Okada K, Akiyama H, Barmer S L. Simultaneous quantitative determination of cilostazol and its metabolites in human plasma by high-performance liquid chromatography. J Chromatogr B: Biomed Sci Appl, 1999; 728: 251-262.

Jadhav S, Pathare D B, Shingare M S. A validated stability indicating high performance reverse phase liquid chromatographic method for the determination of cilostazol in bulk drug substance. Drug Devel Indu Pharm, 2007; 33:173-179.

Nirogi V S R, Kandikere V N, Shukla M, Mudigonda K, Shrivasthava W, Datla P V, Yerramilli A. Simultaneous quantification of cilostazol and its primary metabolite 3,4-dehydrocilostazol in human plasma by rapid liquid chromatography/tandem mass spectrometry. Anal Bioanal Chem, 2006; 384: 780-790.

Physicians Desk Reference. 2005. 59th ed, Thomson PDR at Montvale: New Jersey. pp. 2564-2566.

Siddappa K, Hanamshetty PC, Mane SB, Nagabhushana MM. Development and validation of spectrophotometric method for the determination of cyclophosphamide in bulk drug and its pharmaceutical dosage form. Int J Pharm Pharma Sci, 2013; 5: 597-600.

Siddappa K, Hanamshetty PC. Application of charge transfer reactions for the quantitative spectrophotometric determination of cyclophosphamide in pure and pharmaceutical formulation. Curr Pharm Anal, 2015; 11(2):131-138.
Siddappa K, Hanamshetty PC. Spectrophotometric quantitative determination of Ambroxol hydrochloride in bulk and pharmaceutical dosage forms using PDAB reagent. Int J Pharm Sci Res, 2014; 5(10): 4188-94. doi: 10.13040/IJPSR.0975-8232.5(10).4188-94.

Tata P N V, Fu C H J, Barmer S L. Determination of cilostazol and its metabolites in human urine by high performance liquid chromatography. J Pharm Biomed Anal, 2001; 24: 381-389.

Tata P N V, Fu C H J, Browder N J, Chow P C, Barmer S L. The quantitative determination of cilostazol and its four metabolites in human liver microsomal incubation mixtures by high-performance liquid chromatography. J Pharm Biomed Anal, 1998; 18: 441-451.

Yeon K J, Park Y J, Park K M, Park J S, Ban E, Kim M K, Kim Y B, Kim C K. High performance liquid chromatographic analysis of cilostazol in human plasma with on-line column switching. J Liq Chromatogr Rel Tech, 2005; 28: 109-120.

\section{How to cite this article:}

Kuruba SA, Hanamshetty PC. A simple spectrophotometric quantitative determination of Cilostazol in bulk and pharmaceutical dosage forms using DNPH reagent. J App Pharm Sci, 2015; 5 (12): 117-121. 